\title{
Political News Discourse Analysis Based on an Attitudinal Perspective of the Appraisal Theory-Taking the New York Times' Report China-DPRK Relations as an Example
}

\author{
Jinxiu Jin \\ Shanxi Normal University, China
}

\begin{abstract}
The relationship among China, the United States and North Korea has already been a focus of international politics. From June 19 to 20, North Korea leader Kim Jong-un ended his third visit to China within 100 days. This is also his three consecutive visits to China since he took office in December 2011. The high density and frequency are not only rare in the history of China-DPRK relations, but also seem to be unique in the history of international relations, indicating that China-DPRK relations are welcoming new era. This paper selects the New York Times' report on China-DPRK relations as an example, which is based on an attitudinal perspective of the appraisal theory to analyze American attitudes toward China. Attitudes are positive and negative, explicit and implicit. Whether the attitude is good or not depends on the linguistic meaning of expressing attitude. The meaning of language is positive, and the attitude of expression is positive; the meaning of language is negative, and the attitude of expression is negative. The study found that most of the attitude resources are affect (which are always negative affect), which are mainly realized through such means as lexical, syntactical and rhetorical strategies implicitly or explicitly. All these negative evaluations not only help construct a discourse mode for building the bad image of China but also are not good to China-DPRK relations. The United States wants to tarnish image of China and destroy the relationship between China and North Korea by its political news discourse.
\end{abstract}

Index Terms - political news discourse, appraisal theory, attitude resources

\section{INTRODUCTION}

At the invitation of Chairman Xi Jinping, Kim Jong-un, Chairman of North Korea, paid an informal visit to China from March 25th to 28th. The Chinese side has published a 3,400-word news release, and CCTV News has spent nearly 14 minutes reporting, which is very rare. The main official media of North Korea, such as the Korean Central News Agency, Labor News, and North Korea's CCTV, used a lot of time to report Kim Jong-un's visit to China. It can be seen that both China and the DPRK attach great importance to Kim Jong-un's first visit to China, which is of great significance. This will have far-reaching positive effects on current and future China-DPRK relations and regional situation. The geo-effect and strategic value brought by this visit are enormous.

The meeting between Chairman Xi Jinping and Chairman Kim Jong-un has sensationalized the whole world. In the past few days, the attention of the international community has continued unabated and has been highly valued. This strongly reflects that China-DPRK relations are of great significance to the region and the world at the same time. It also fully demonstrates that China has an irreplaceable key role in promoting the easing of the situation on the peninsula.

The news is generally considered to be a fair and true response to the facts of the public, that is, the reporter collects factual materials, and then objectively reports, presenting the truth of the facts unbiased to the public. News has a certain social nature, and news reports will have certain selectivity, reflecting its social aspect and reflecting the ideology of certain social groups. Because news is presented to the readers in the form of language, language is a social symbol. Therefore, in news reports, the content meaning of news discourse has certain implicitness. Although the ideology implied by it does not have other popular discourses such as news commentary, but because news reports are of an official nature influenced by the mainstream ideology of the ruling class, the reporters must objectively and accurately report the speech activities of government agencies and leaders, and also perform their own media roles, and the media orientation also affects the ordinary people. Therefore, news reports also directly or indirectly influence and control people's way of thinking, and play an important role in the formation of people's attitudes and opinions about social events. Although Western newspapers are in a free social environment, they face fierce competition. In order to survive, news reports will be presented to readers in the way that they are expected by political groups, social groups, and interest groups, reflecting specfic interests, political opinions, and ideologies. From this we can see that political news reports will also reflect the political intentions and ideologies of specific groups.

The political news Beijing Said to Abide by Sanctions on North Korea, for Now published in New York Times. This 
news appears to be a report on China's compliance with sanctions against North Korea, but in fact, by analyzing the news based on an attitudinal perspective of the appraisal theory, we can conclude that the United States wants to provoke China-DPRK relations.

\section{LITERATURE REVIEW}

There are many researchers based on an attitudinal perspective of the appraisal theory to analyze political news discourse. Chen Mei published A Study of English Translation of Bai Juyi's Poems from An Attitudinal Perspective of the Appraisal Theory in Foreign Language Education. This paper studies the English translations of Bai Juyi's poems by focusing on attitude in appraisal theory. Through a comparative and statistical analysis of the affect, judgment, and appreciation in Levy's 10 English translations of Bai Juyi's narrative poems, this paper demonstrates that Levy's evaluation strategies chiefly lie in his increasing attitude resources and decreasing affect resources, different frequency and distribution of positive/negative attitude resources between Levy's translation and Bai Juyi's original poems (Chen,2013). An Analysis of Britain's Attitude towards the "One Belt and One Road Initiative" from the Perspective of Appraisal Theory was written by Zhao Yaying. Based on Martin's appraisal theory, this paper penetrates into Britain's attitudes through analyzing the reports written by three major British presses with quantitative approach.This study aims not only to provide some suggestions for "one belt and one road" publicizing but also to present a way of analyzing intelligence with quantitative approach, and to enlighten related studies.It has been found that Britain holds positive attitudes towards "one belt and one road" on the whole. Britain worries about this initiative, such as the turbulent Middle East and the matter of sharing profits, but still it is attracted by the great potential and outlook and it regards "one belt and one road" as an opportunity to revive its stagnant economy (Zhao,2016). Wang Qiang wrote a paper named News Review Analysis With Appraisal Theory _ Based on the Indian Review on the Belt and Road. In this paper he discovered that the affection resources and judgment resources are highly frequent. There is significantly correlation between positive affection and positive judgment. The news reviews are constructed based on positive affection evaluation so that readers may follow its direction and develop positive attitude (Wang, 2016). Chen Lingjun published News Discourse of Chinese Dream: An Attitudinal Perspective of the Appraisal Theory in 2016. With Martin and White's appraisal theory as the theoretical framework for discourse analysis, this study adopts qualitative and quantitative methodologies to analyse the implicit and explicit attitudinal resources in Chinese dream news discourses chosen from Chinese authoritative sources of China Daily and Xinhua News Agency (Chen, 2016).

Many researchers analyzed political news discourses from an attitudinal perspective of the appraisal theory, especially in recent years. The author would also do in the same way, but with a more clear and detailed way to classify the attitude resources to analyze the news discourse.

\section{THEORETICAL BASIS}

The significance of the evaluation derives from the study of attitudes, emotions and judgments in 1985, but did not form a certain theoretical system at the time. Martin extended this research to the level of discourse analysis. From 1991 to 1994, he hosted a research project called "Write It Right", which launched a study on the language proficiency of institutions in secondary schools in Wales, Australia. Martin then worked with White to create a model structure for the appraisal system. In 2000, Martin published a paper Beyond Exchange: Appraisal Systems in English officially proposed the appraisal theory system. The appraisal theory is the development of interpersonal meaning under the theoretical framework of systemic functional linguistics. It mainly studies how the speaker or author expresses his subjective attitude in words. Like other theories of systemic functional linguistics, appraisal theory emphasizes the rhetorical choice of linguistic resources, which is the study of language assignment semantics, and builds a large and sophisticated system to study how language users can give language objects through language. The value of meaning and the strategy of constructing one's own position or discourse sound, the realization of interpersonal meaning helps the listener/reader to better understand the position, viewpoint and attitude of the speaker/author and realize interpersonal interaction. The appraisal theory consists of three main systems, namely attitude, engagement and graduation. This paper mainly studies specific news discourse from the perspective of attitude system.

According to Martin's interpretation and classification, attitude is the most complex part of the appraisal system.

Attitude refers to the judgment and appreciation of human behavior, text/process, and phenomenon. It is the object of the language user's description (the attitude of object, thing, and person), but this is the perspective of the reader based on the language of the text. Attitude is divided into three subsystems: the judgment system, the affect system, and the appreciation system (Wang, 2001). The affect system is the center of the entire attitude system, from which the judgment system and the appreciation system are derived. Specifically, the affect system is a resource for interpreting linguistic phenomena and is used to explain the emotional reactions of language users to behaviors, texts, processes, and phenomena. As a resource for interpreting emotional language phenomena, the judgment system is used to explain the moral judgment of language users on certain behaviors according to ethics/morality, rules/systems, such as whether they are ethical, reliable, and brave or not. As a resource for interpreting linguistic phenomena, the appreciation system is used to explain the appreciation of the aesthetics of texts/processes and phenomena by language users. In short, as Martin said, they are the resources of choice for emotional performance, moral judgment, and aesthetic evaluation (Liu, 
2013).

Attitude can be positive or negative, and can be either explicit or implicit. The affect system can be divided into affect as quality, affect as process and affect as comment. Judgment system is an ethical category, which is the judgment and evaluation of human personality and behavior. The system can be divided into social esteem (related to the behavioral norms of the evaluation object, ability, tenacity, etc.) and social constraints (related to the ethical concept of whether the evaluation object is true and reliable, and whether the behavior is justified). The appreciation system is an aesthetic category, which is used to express our evaluation of things, mainly including things we manufacture or realize (Martin, 2005) .

\section{Analysis of Attitude Resources of News Discourse in ChinA-DPRK Relations}

In this part, the writer first introduces the resource of the corpus, as well as the reason why the writer chooses this news as corpus. Then, the writer from three aspects, namely affect, judgement and appreciation, analyzes American attitude toward China.

\section{A. Corpus Source}

The corpus of this paper was adopted from New York Times. New York Times, sometimes referred to as The Times, is a daily newspaper published in New York, USA, and has a high degree of influence. It is the representatives of senior American newspapers and serious publications. New York Times has a good credibility and authority. Due to the classic style, it is sometimes dubbed "The Gray Lady". Its original name was The New York Daily Times, and the founders were Henry Jarvis Raymond and George Jones.

In the news report, the New York Times saw itself as a "newspaper record". The result of this policy was that the New York Times rarely reported an incident first, except for local news in New York. And if it really reports an event first, then the reliability of this report is very high, so it is often used as a source of news directly by other newspapers and news agencies around the world. A New York Times index is available in most public libraries in the United States, and its content on New York Times' article is latest events. The New York Times has a reputation for being a reliable source of news. Its editorial is generally considered to be relatively open. But in fact its editorial is written by many different authors, and their views vary from left to right.

But for the media, national interests have priority over their rights and freedoms, and the media must give top priority to national development goals. New York Times is also included in the media. News is for political service, and has always been closely connected with politics, and the principle of the supremacy of national interests is upheld. Due to the huge differences in social systems, political systems, and ideologies between China and the West, the big Western countries have unscrupulously curbed the rapid rise of China, and some mainstream media reports concerning China have added fuel to the flames and wantonly vilified China. They exaggerate the strategic competition of great powers, China threatens.

\section{B. Attitude Resource Analysis}

Attitudes are positive and negative, explicit and implicit. Whether the attitude is good or not depends on the linguistic meaning of expressing attitude. The meaning of language is positive, and the attitude of expression is positive; the meaning of language is negative, and the attitude of expression is negative. Both positive and negative attitudes have explicit or implicit characteristics. When the linguistic meaning of expressing an attitude is revealed by the literal meaning of the language, the attitude is explicit; when the linguistic meaning of expressing the attitude is revealed by the meaning behind the language, the attitude is implicit. Implicit attitude is not only related to context, but also to the semantic responsibility of language users.

In the appraisal system, emotions are mainly concerned with the semantic resources of emotions of people, things, events or situations. Martin divides emotional resources into four categories, namely, Un/happiness, In/Security, and Dis/satisfaction, and Non/Pursuit. The judgment system belongs to the ethical category and evaluates the behavior of language users based on ethical standards. Judgment can be divided into two parts: social esteem and social sanction. Appreciation system is an aesthetic category, which refers to the aesthetic evaluation of texts/processes and phenomena, and also has positive and negative meanings. Appreciation can start from three perspectives: reaction, composition, and valuation. China, Chinese, Beijing, are mentioned very frequently in the political news Beijing Said to Abide by Sanctions on North Korea, for now. There are many attitude resources in this political news.

\section{Affect Attitude Resource}

Maritin and White refer to the person who consciously experiences the emotional experience as the emoter, and the phenomenon that causes the emotion is called the trigger. There are six aspects to consider when classifying emotions: the first is whether they positive or not (eg. He is happy. / She is sad.) ; the second, is there any accompanying external action or purely internal state (eg. She wept. / She is sad.); the third, is it for the specific trigger (eg. She is distressed. / She feels proud about her child); the fourth is the intensity of the emotion (eg. The captain disliked leaving. / The captain detested leaving.); the fifth, with or without subjective intentions (He disliked leaving. / He feared leaving.); the sixth is the classification by content (sad-happy; anxious-confident; fed up-absorbed) (Liu, 2013).

There are many negative affect attitudes in the corpus. In the first example, the word angered involves negative affect 
expression which implies that the United States has shown that China is acting in its own interest, regardless of the overall situation, on North Korea peninsula issue. The United States, by twisting the facts, aims to destroy China's image and put pressure on China.

(1) Such an image would seem to bolster Mr. Trump's suggestion that China, angered by American tariffs on its goods, was no longer a partner in the effort to disarm the North.

In the second example, the word suspicions involves the expression of emotional intent, expressed through this emotional word to drive a wedge between the China and North Korea. This is because from June 19 to 20 , North Korean leader Kim Jong-un ended his third visit to China within 100 days. This is also his three consecutive visits to China since he took office in December 2011. The high density and frequency are not only rare in the history of China-DPRK relations, but also seem to be unique in the history of international relations, indicating that China-DPRK relations are welcoming a new era. The United States doesn't want to see the relationship between China and North Korea getting better and better, so here in the American press, the word is used to separate the two countries.

(2) China, they say, still harbors deep suspicions about the North and Mr. Kim, despite the recent thaws in the neighbors off-and-on relationship.

In the third example, intensity, passive, both of these words express negative, passive emotional attitudes. The United States uses trade war as an excuse to smear China, saying that China, because of the trade war between the United States and China, is unwilling to assist U.S. President Trump to resolve North Korea peninsula issue. In fact, that is not true. This is very bad for China's image in the world.

(3) Still, he said, the intensity of the trade war with the United States, along with the increasing likelihood that it will become a protracted standoff, has led China to be more passive about assisting Mr. Trump on North Korea.

The word burned is also affect attitude in the fourth example. This is because Sino-US trade relations have developed in friction and twists since the two countries established trade relations. Recently, trade relations between China and the United States have deteriorated, and China has been reluctant to bow to American power. Therefore, the US media wants to distort the facts to worsen China's image in the world, and to put pressure on China in order to make China bow to the US power. China's accession to the WTO with the development of economic and trade relations between the two countries, the frequency of trade friction has increased, and the United States has become the country with the most trade friction with China. More than $20 \%$ of US companies' dumping allegations against overseas competitors involve China. Despite the huge US market and the rapidly rising Chinese market, as well as the increasingly close economic and trade exchanges, these two countries have huge economic interests with each other, but such fierce trade frictions can not help the prospects of Sino-US economic and trade relations. American trade is not a simple economic decision, but a balance between economic interests and political reality.

(4) China is less interested in backing the denuclearization efforts because it feels burned by Mr. Trump on trade, according to a Western diplomat with contacts among the Chinese leadership. Its leaders had believed that Mr. Trump would not proceed with the confrontational trade policies he promised during the presidential campaign if China helped him by going along with tougher United Nations sanctions against the North last year, the diplomat said.

Although there are two positive affect attitude words in the beginning of the sentence, there are also two negative emotional words in the ending of the sentence. China-DPRK relations are gradually on the right track and relations are getting better and better. The United States wants to provoke relations between China and North Korea. The United States wants to suggest that the relationship between China and North Korea is neither stable nor secure.

(5) I very much expect this visit could happen, and it would greatly improve bilateral relations, Lu Chao, director of the Border Study Institute at the Liaoning Academy of Social Sciences, said of Mr. Xi's trip. Sept. 9 is a particularly meaningful date for North Korea, and Mr.Xi's presence would further strengthen a relationship that is warming but still not secure, he said.

From the above examples analysis, we can conclude that most of the attitude resources used in this report are negative attitude resources. Behind these negative attitude resources is that the United States hostile to China, and the United States wants to discredit China, and to undermine the image of China in the international. At the same time, the US also wants to undermine China-North Korea relations, making China's geopolitical relationship more complicated and worse.

\section{Judgement Resource Analysis}

The judging system is based on the ethical, moral and social statutes of the commentator's actions, and whether the praise or condemnation is made. Social judgment judges the personality and behavior of a person from the three perspectives of normality, capacity, and tenacity. It is judged whether a person's behavior is in line with the routine, whether it is talented, and whether it is strong. This criterion of judgment is often verbal and there is no written provision. Social constraints mean judging the positive and negative meanings. The positive meaning makes people envious, the negative meaning should be criticized, but the criticism is not in the legal sense, and the criticized behavior is not malignant. Social constraints are also positive and negative. The positive meaning is praise, the negative meaning is condemnation, and the condemnation behavior has legal meaning.

There are several examples of judgement resource analysis in this news discourse. In the first example, blame refers to condemn China. It is a judgement resource which suggests that China should responsibility for the Korean peninsula issue. However, in fact, the responsibility for the Korean peninsula issue lies mainly with the United States, while the 
United States puts the responsibility on China.

(1) BEIJING -- When President Trump said on Friday that there had not been sufficient progress toward ridding North Korea of its nuclear weapons, he made it clear that he thought China was partly to blame.

The word, punish, in this sentence refers to judgement resource. In this sentence, the American press reported that China punishes North Korea in order to provoke the contradiction between the two countries.

(2) China, they say, still harbors deep suspicions about the North and Mr. Kim, despite the recent thaws in the neighbors off-and-on relationship. And while it is giving the North some economic help around the edges, they say,China is mostly abiding by the international sanctions meant to punish Pyongyang for its nuclear pursuits.

\section{Appreciation Resource Analysis}

Appreciation system is an aesthetic category, which refers to the aesthetic evaluation of texts/processes and phenomena. It also has positive and negative meanings. Appreciation can start from three perspectives: reaction, composition, and valuation. However, there is almost no positive appreciation resource in this political news which indicates America does not appreciate China.

\section{CONCLUSION}

From the above analysis, we can see that the attitude resources of this political news are mostly affect attitude resources, and also negative affect attitude resources. There are some judgment attitude resources, while appreciation attitude resources are almost none. Since recent days, North Korea leader Kim Jong-un frequently visit China which makes the relations between the two countries have been advancing by leaps and bounds. America is unhappy to see this. Therefore, US is going to damage the relations between the two countries through this report, and discredit China's image in the world. From the analysis of this news report, we can conclude that the United States is hostile to China. This is conducive for the Chinese people to come and understand America's intentions.

\section{REFERENCES}

[1] Chen Mei \& Wen Jun. (2013). A Research on the English Translation of Bai Juyi’s Poems from the Perspective of Attitude in Appraisal Theory. Foreign Language Education, 4, 99-104.

[2] Chen LingJun \& Zhao Chuang. (2016). News Discourse of Chinese Dream: An Attitudinal Perspective of the Appraisal Theory. Journal of Tianjin Foreign Studies University, 4, 34-39.

[3] Jane. Perlze. (2018). Beijing said to abide by sanctions on North Korea, for now. New York Times, 8, 10.

[4] Kang Junying \& Li Fengqin. (2018). A Critical Analysis of Reporting Verbs in Political News Reports--A Case Study of South China Sea Dispute News Reports from New York Times. Foreign Languages Research, 3, 25-30.

[5] Liu Runqing. (2013). Schools of Linguistics. Beijing: Foreign Language Teaching and Research Press.

[6] Martin, J.R. (2000). Beyond Exchange: Appraisal Systems in English. Evaluation in Text, 9, 142-175.

[7] Martin,J.R. \& P.White. (2005). The Language of Evaluation: Appraisal in English. New York Palgrave Macmillan Ltd.

[8] Wang Zhenhua. (2001). Appraisal System and Their Operation: A New Development in the Systemic Functional Linguistics. Journal of Foreign Languages, 6, 13-20.

[9] Wang Zhenhua. (2004). An Appraisal Approach to Hard News in Both English and Chinese. Foreign Language Education, 5, 31-35.

[10] Wang Qiang. (2016). News Review Analysis With Appraisal Theory-Based on the Indian Review on the Belt and Road. Journal of Harbin University, 1, 134-136.

[11] Zhang Huanyu. (2010). Analysis of Attitudes in Reports of North Korea Nuclear Issue. Journal of Anhui University of Technology, 27, 88-91.

[12] Zhao Yaying \& Guo Jirong \& Che Xiangqian. (2016). An Analysis of Briain's Attitude towards the "One Belt and One Road Initiative" from the Perspective of Appraisal Theory. Journal of Intelligence, 10, 38-41.

Jinxiu Jin was born in Shanxi, China in 1994. She received her bachelor's degree in English Education from Lvliang University, China in 2017.

She is currently a graduate student in the School of Foreign Languages, Shanxi Normal University, Shanxi, China. Her research interests include pragmatics and English language teaching. 